\title{
How to Run Together: On Study Abroad and the ASD Experience
}

\author{
Araceli Masterson-Algar \\ University of Kansas
}

Brian Jennings

Albright College

Mark Odenwelder

Study New Mexico USA

\begin{abstract}
:
The growing offering of study abroad programs across university campuses seemingly disregards the large numbers of students with disabilities accessing higher education. Given that study abroad experiences are becoming expected and, in many institutions, mandatory requirements towards graduation, it is imperative that accommodations, as well as course design, for disabilities, be addressed. Furthermore, the promotion of study abroad programs as a means to develop some sort of "cultural literacy" demands attention to the cultural processes surrounding perceptions of and responses to disability, which are, above all, culturally specific. Through two case studies in Cuenca, Ecuador, we address some of the challenges and opportunities associated with the participation of two high functioning ASD students in the study abroad experience.
\end{abstract}

\section{Introduction: Higher Education, Study Abroad, and Autism Spectrum Disorders}

In the academic year 2015-2016, a total of 325,339 U.S. students studied abroad, a 3.8\% increase from the previous year and a 57.9\% increase from the 205,983 students in 2004-2005 (Institute of International Education [IIE], 2017a). This growth has come in the form of an expansion of short-term programs (less than eight weeks in length): $52.1 \%$ of U.S. students participated in such programs in 2004-2005 compared to $60.2 \%$ of students in 2014-2015 (IIE, 2017b). ${ }^{1}$ The overall rise in the number of U.S. students studying abroad runs parallel to the growing number of students with disabilities engaging in these experiential opportunities. ${ }^{2}$ One possible

\footnotetext{
1 The top destinations for U.S. students have also shifted. Europe has decreased from the turn of the century, with $63.1 \%$, to $54.4 \%$ in 2015-2016, while Latin America remains the second most popular region as the destination of $16.3 \%$ of students on U.S. programs abroad (up from $14.5 \%$ at the turn of the century). Finally, programs to Asia have nearly doubled their numbers, with an increase as choice of destination from $6.0 \%$ to $11.1 \%$ (IIE, 2003; IIE, 2017c).

2 In 2006-2007 (the first year students with disabilities were tracked), only $2.6 \%$ of students reported a disability, while in 2015-2016 the percentage grew to 8.8\%. According to this data, the categorizations of students with disabilities participating in study abroad programs include learning disabilities, mental disabilities, physical disabilities, sensory disabilities, and other disabilities. In the nine years that these statistics have been tracked, students with learning, physical, and sensory disabilities have declined in terms of their percentage of participation,
} 
explanation for this increase may be the larger offering of short-term programs, which arguably provide students with more confidence that they can adjust to and overcome any challenges presented due to the shortened experience. While campuses nationwide are increasingly aware of the need to respond to the growing numbers of students with disabilities, there is a notorious absence of literature addressing this population and the study abroad experience.

The data from the IIEs Open Doors Report, however, should be used primarily for orientation, as this data on students with disabilities is relatively new, and thus its scope can be limited and its numbers underreported. Nevertheless, IIE's website does not address whether the response rate is in fact exclusively from U.S. institutions, potentially erasing the differences between the variety of institutions reporting on their numbers of students studying abroad and those that do not.

The estimated number of college students with disabilities in the United States is three million, approximately 11\% of all college students (National Center for Education Statistics, 2015, cited in Ingersoll, 2016). The challenges that these students face add to the continued barriers in the provision of inclusive opportunities in higher education. Opportunities such as study abroad have been alluded to as an important piece of student retention strategy (Metzger, 2006). According to Tinto (1993), an important factor in the decision of a student to stay at an institution is their perception of a rewarding experience. As such, study abroad has been shown to provide rewarding and lasting effects, both academically and personally (Dwyer, 2004). Therefore any barriers to inclusive opportunities in higher education, especially study abroad, help to contextualize a national dropout rate that rises to $70 \%$ for students with disabilities. (Lightner, Kipps-Vaughan, Schulte, \& Trice, 2011, cited in Ingersoll, 2016). These statistics, although alarming, are the outcome of a historical absence of students with disabilities from higher education until barely four decades ago, when the Individuals with Disabilities Education Act (1975) was implemented. The growing offering of study abroad programs across university campuses seemingly disregards the large numbers of students with disabilities accessing higher education.

Given that study abroad experiences are becoming expected and, within many majors at many institutions, mandatory requirements towards graduation, it is imperative that we take a critical stance that addresses how cultural understanding can be acquired and whose cultural competence is valued. Furthermore, the promotion of study abroad programs as a means to develop some sort of "cultural literacy" demands attention to the cultural processes surrounding perceptions of and responses to disability, which are, above all, culturally specific (Armstrong \& Barton, 1999). In other words, it is not enough to include students with disabilities in study abroad programs. Rather, the call is to understand that in seeking cultural literacy, study abroad curricula must necessarily address the cultural processes at work in the construction and perpetuation of experiences of disability at home. Thus, comprehensive responses to disability by advocates and promoters of study abroad experiences must turn these individuals' expertise into initiatives that understand the acquisition of cultural understanding as inseparable from efforts to address reductionist perceptions of oneself and others. In this paper we focus specifically on students with autism spectrum disorders (ASD).

while the categories for mental and other disabilities have more than doubled in terms of their percentage (IIE, 2017a). 
Through two case studies in Cuenca, Ecuador, we address some of the challenges and opportunities associated with the presence of students with ASD in the study abroad experience.

Recently, Link (2016) and Twill and Guzzo (2012) discussed inclusivity in study abroad but focused on physical and sensory disabilities, such as various forms of immobility and blindness. Prohn, Kelley, and Westling (2018) explored study abroad for students with intellectual disabilities such as Down syndrome and cerebral palsy. In each of these recent papers, authors came to the conclusion that inclusion of students with varying disabilities was possible, but required collaborative efforts among the offices of international education, offices of disability services, and program leaders. These examples are noteworthy but it is also true that they all encounter a continued ambiguity regarding whether or not institutions of higher education are required to provide adequate accommodations under relevant disability laws (Twill \& Guzzo, 2012).

The last decade has seen an emergence of literature on higher education and students in the autism spectrum, comprising a considerable corpus addressing college personnel, faculty, counselors, parents, and also students themselves. With a focus on college personnel, Wolf, Brown, and Bork (2009) comment on the "spike" in diagnoses of autism spectrum disorders, and call attention to the ways in which "the college environment can be uniquely equipped to help these students gain independence and become functional, gainfully employed adults" (p. 3). Various authors offer guides to college success for students with disabilities (Ingersoll, 2016), while others address the process of leaving home more broadly (Muggleton, 2012). In addition, multiple works offer comprehensive checklists and useful tools for universities to better assess, and thus respond to, the specific needs of students in the autism spectrum (Wolf, Brown, \& Bork, 2009). Many of the latter include long appendices with lists of resources for students, parents, and facilitators, as well as annotated resources on various topics related to autism spectrum disorders (Katovitch, 2009; Zager, Alpern, McKeon, Maxam, \& Mulvey, 2013), and overviews of successful programs for students with ASD across institutions of higher education in the United States.

The literature combines theory and praxis, addresses students and university personnel alike, and illustrates the move away from medical models of ASD to its understanding as a cultural identity (Autistic Self Advocacy Network [ASAN], 2013). An exploration of the study abroad experiences of students in the spectrum, as well as their faculty and program providers, is essential to ensuring not only inclusiveness but also positive experiences for all involved. ${ }^{3}$ Yet, not one source addresses study abroad for students with ASD. In fact, students with ASD are expected to move in a linear trajectory from their home to the college, then to their labor niche. It is therefore assumed that students with autism and Asperger's will not engage in activities outside of the campus space prior to employment or for any purpose other than an internship. Therefore, the lack of literature

\footnotetext{
${ }^{3}$ Various authors have noted the increasing numbers of people diagnosed with autism spectrum disorders (Wolf et al., 2009; Zager et al., 2013; ASAN, 2013; and Muggleton, 2012). According to Zager et al. (2013), an estimated 673,000 people in the United States have autism spectrum disorders. These numbers are particularly salient for children and youth. Thus, "[b]etween 1994 and 2006 the number of children from 6-17 years old identified with ASD in public schools increased from 22,684 to 211,610, approximately 90\%" (Zager et al., 2013, p. 4). On their part, Kogan and his colleagues cite figures from the Center for Disease Control indicating that 1 in 90 children between the ages of 3 and 17 are on the autism spectrum (Zager, 2013, p. 4).
} 
on experiential learning in higher education for ASD students, beyond internships, creates the premise that these students will not travel. By doing this, we argue, these sources perpetuate the ideological limits on human possibility that they set out to critique. Therefore, we must turn to the lived experiences of this growing student population to question these assumptions.

Muggleton (2012) writes from the perspective of someone with Asperger's. He outlines three main areas of difficulty for people with Asperger's: communication, social interaction, and imagination. The author emphasizes that the impaired imagination does not translate into the inability to imagine, but rather is "the tendency to think in an inflexible way" (p. 38). Ironically, these three difficulties sum up the learning outcomes of any study abroad experience.

\section{Students with ASD: Cultural Observers at Home}

Goffman (1963) reflected on the experience of marginalized members of society vis-à-vis social rules and norms. According to Goffman, rules of social interaction are taken for granted and even when broken, they remain mainly invisible, further contributing to judgments on those who "break the rules" as "problematic" or suffering from mental disorders. Following from Goffman, Garfinkel (1967) noted the central role of the "stranger" in making these invisible rules visible. Both Goffman and Garfinkel formed what are called ethnomethodologies to study these "invisible" patterns of social interaction. They conducted a series of breaching exercises, whereby the researcher breaks some form of a social norm in order to unveil the rules regulating social interactions. These social norms are culturally specific, and therefore extremely relevant in study abroad experiences. Feeling like a "stranger" is no doubt central to the study abroad experience, but for the student with ASD this experience takes particular salience.

Patricia Hill Collins, a black feminist theorist, turns to George Simmel's analysis of the "stranger." Simmel (1921) outlined three benefits of being a stranger or an outsider: First, the stranger possesses a unique form of objectivity by being both near and remote to situations while also possessing concern and indifference simultaneously; second, people are more likely to confide in strangers than in members of their own groups; and third, the stranger is more equipped to identify patterns that are often invisible to ingrained group members. No doubt, a student with ASD is familiar with the experiences of being a stranger. Arguably, students with ASD are by their very condition ideally suited to reflect on society's norms and behaviors, and have had a lifetime of training on how to think of themselves in relation to others' cultural expectations.

Patricia Hill Collins's (1999) concept of the “outsider within" draws from Simmel, but with specific attention to black feminist thought and therefore to the intersectionality of social hierarchies. She refers to border spaces, or more specifically to the space between social groups that possess unequal power in society. The black woman, she argues, is, due to her condition as an "outsider within," a central asset in unveiling and dismantling interlocking systems of oppression affecting society at large. For instance, she argues, black women working in service could more readily identify the "oppression" of the white woman than the white woman herself. According to Collins (1999), there are also problematic contradictions in these spaces. While individuals may appear to possess the necessary traits for membership in a particular group, and therefore the rights of that particular group, they often may not be afforded all of the experiential benefits that other members enjoy. They belong therefore to the space between groups, and have faced the need to 
navigate a variety of contexts. Other feminists of color have worked from this same awareness, (re)framing exclusion as the very source of power from which to (re)act from within. Gloria Anzaldúa (1987) describes this power as the "facultad" of her "mestiza consciousness," and Chela Sandoval (2000) reframes it as "oppositional consciousness."

Individuals with ASD, and specifically in high-functioning expressions, no doubt possess much of the experiences outlined above for the "stranger" and for the "outsider within," and thus can be in a position to understand the study abroad experience in revealing ways. Albeit not always intentionally, their experiences in study abroad programs can unveil some of the "invisibilities" of these educational experiences, thus opening spaces for critical thinking and improvement. Yet, their journey is rarely addressed through the lens of critical feminism that would, among other things, contemplate interlocking systems of power shaping the human experience in specific time and space.

Thus, while institutions and students turn to race, ethnicity, class, gender, and sexuality as spaces to address "cultural organizing," this is not so for disability. In a volume by the Autistic Self Advocacy Network (2013), Cara Liebowitz calls for the creation of disability cultural centers at institutions of higher education. She rightly highlights the "glaring absence" of disability "from a litany of campus cultural hubs" and identifies the persistence of the medical model of disability as central to its exclusion from other identify markers such as race, gender, or sexual orientation. As she puts it, disability continues to be perceived as "an unfortunate event that happens to you, not a unique identity that belongs to you" (p. 81).

The concept of the "outsider within" proves most useful in that it reaffirms the so-called "outsider-victim" as a social actor, and thus, as a source to understand social inequality at large. Under this light, definitions of disability as "disease" turn into questions of disability as a social, political, and by all means cultural phenomenon. This is precisely the framework for Disability Studies. As described by Allegra Scott, from the Autistic Self Advocacy Network:

In contrast to clinical, medical, or therapeutic perspectives on disability, Disability Studies focuses on how disability is defined and represented in society. It rejects the perception of disability as a functional impairment that limits a person's activities. From this perspective, disability is not a characteristic that exists in the person or a problem of the person that must be "fixed" or "cured." Instead, disability is a construct that finds its meaning within a social and cultural context. (2013, p. 100)

But the choice of the term "outsider within" is particularly resonant to students with ASD. After all, the three main difficulties of ASD—communication, social interaction, and imagination-place people with ASD in positions where they are necessarily observant of so-called "culture." The third difficulty, imagination, refers not to the inability to imagine, but rather the tendency to think in an inflexible way (Muggleton, 2012, pp. 29-30). All three of the aforementioned challenges frame students in this group as "outsiders," while opening a window for study abroad providers and faculty to "other" forms of thinking that can strengthen the pedagogical and personal experiences of our programs.

In order to open richer spaces from which to reflect on the study abroad experience as a whole, we contemplate two case studies of students with ASD who participated in study abroad programs 
in Cuenca, Ecuador. Both are illustrative of the challenges encountered, outcomes for students (both those with and without disabilities), and the structures that need to be implemented to ensure a successful study abroad experience for participants with ASD. The first case illustrates many things that can go wrong when including a student with ASD in the study abroad experience, whereas the second, largely a success story, is illustrative of the opportunities that addressing the reality of students with ASD offers to the student and to the study abroad experience as a whole. These case studies, each with very different outcomes, are windows to better understand the need to critically address the experience of students with ASD. Goffman's (1959) reflection on the experience of marginalized members of society vis-à-vis social rules and norms, Simmels's (1921) notion of the "stranger" and, finally, an understanding of the experience of the student with ASD as that of an "outsider within," following from Black feminist theorist Patricia Hill-Collins (1999), signal us to think about how certain members of the larger society have experiences and ways of experiencing that are central to addressing inequity at large. The experience of students with ASD can, we argue, challenge the ways we think about the study abroad experience, and thus positively contribute to its design and outcomes.

This case study was created by three authors who believe strongly in the power of study abroad to transform lives, both personally and academically. AM, a bicultural educator, brings years of experience teaching and leading study abroad courses, in addition to having been born and living in different countries at different stages of her life. BJ is a white male from the United States who has been leading study abroad courses for ten years. He was the first person in his immediate family to earn a Bachelor's degree and did not study abroad in college. MO is a white male who lived in Ecuador for nearly 15 years as a result of studying abroad and later working there. His background as a school teacher in addition to being the director of an international Pre-K through 12 school gave him familiarity with working with students with ASD in an educational environment, though not necessarily a "day to day living" situation. While under MO's leadership, the school was recognized by the national government for inclusive excellence.

The faculty leaders and the in-country program partner worked together to ensure program success, with their responsibilities generally being divided in the following way: As faculty, the authors were responsible for the development of the curriculum of the course, recruitment of students, pre-departure orientation, and course instruction; the in-country program partner was responsible for all travel logistics, securing appropriate host family matches, selecting local faculty for classroom instruction, determining the most beneficial site visits based on the course content provided by the visiting and local faculty members, and ensuring that the health and safety of students was considered at all times.

\section{Case Study 1: Running After Cassidy}

Cassidy was a junior at a small liberal arts college when she enrolled in the "Interim in Ecuador" program. The course for that particular year used sociology to situate the students' immersive experience in a culture different from their own. Two faculty members led the three-week immersive experience, which provided students with the opportunity to live with an Ecuadorian family and experience firsthand much of the Ecuadorian culture. While enrolling students for the course, one faculty member indicated interest from many students, including Cassidy, who was shortly characterized as a "little different." 
As the course drew near, Cassidy's parents requested a conversation to discuss the course and the experience. They did not provide any specifics about Cassidy's condition, but did indicate that, when overwhelmed, her coping mechanism was to "run" and to play video games. The course faculty and the host institution were certainly able to accommodate such items through proper host family selection and exercise. As the conversation with Cassidy's parents seemed to go well, her participation in the course ensued.

Yet, all conversations prior to departure and the pre-course paperwork provided no indication of the extent of Cassidy's disability, much less any insights into possible adjustments and responses. The required medical forms that each student must complete did list Cassidy's prescription medication, but offered no details as to why such medication was required. We therefore proceeded to share some initial concerns with our in-country partner requesting a family situation that would be most conducive to a successful experience for Cassidy. In response, our partner easily matched Cassidy with a family that had an impeccable history of hosting students, and a child of Cassidy's age who liked to play video games.

One of the biggest immersive experiences is taking part in the home life of an Ecuadorian family. But upon her arrival in Ecuador, it became evident that Cassidy would struggle with being out of her normal routine. Instead of getting to know her host sibling or interacting with her host family, she spent most of her time in her bedroom on her tablet. The host mother approached faculty asking for help. She was concerned for Cassidy's general well-being, as Cassidy spent much of her time talking to herself and isolated from spaces for family interaction. In addition, the need to get to and from class each day in a new city proved to be too much for Cassidy. She indicated she felt unable to navigate the city safely (both directionally and out of fear). In collaboration with her host family, our partner institution worked out an arrangement for taxis to drive her back and forth every morning and afternoon.

In the classroom, the situation proved equally challenging. The coursework required from students in a short-term study abroad context is quite intense. Three hours in the classroom, even with breaks, proved to be difficult for Cassidy. She would often shake to the point of being disruptive to the other students (and faculty) and would occasionally leave the classroom in the middle of class saying, "I need to go for a walk." Given her inability to navigate the city alone, this caused major disruptions, as one faculty member would need to accompany her on her walks. Experiential courses such as this one require much more than time with the host family and in the classroom. Traveling and being part of a group brought up a whole set of challenges for Cassidy, and in turn, for faculty, students, and staff. Cassidy had trouble following instructions and understanding short- and long-term schedules. We would set departure times, but would find Cassidy unready in her room at the scheduled time. She would often show up to planned excursions without the needed materials, or seemed completely unaware of meeting times.

To illustrate the reasons for our shared concern, one particular instance stands out. While visiting a small indigenous village, a faculty member reminded Cassidy that she needed to be ready for the scheduled departure times. This interaction caused Cassidy to run out of her room and down a hillside into unfamiliar territory. Faculty needed to chase after her and force her to return. Due to this event, Cassidy was not allowed to attend the scheduled event for that morning and was required 
to stay at the hostel under the supervision of a faculty member. The next day, Cassidy continued her erratic behavior by nearly jumping off a moving open-air bus. She later explained her behavior as a result of being upset because the television in the room at the hostel did not work. On the return trip to Cuenca, Cassidy also grew increasingly upset because her tablet was no longer working. We explained that it was likely because she had forgotten to charge it the night before, but she insisted that the curandero (native healer) was to blame.

From an administrative perspective, Cassidy's attempt to jump from the bus brought us to the point of considering sending her home. This possibility proved difficult on many levels. We had never sent a student home before and the institutional procedures were not well flushed out. More importantly, the logistical problems associated with getting Cassidy to the international airport and safely on numerous flights back to her parents was cause for concern, particularly because Cassidy's communication with her parents throughout the trip had been, to our surprise, non-existent.

We need to be clear that while Cassidy struggled with these classroom situations, she was certainly able to accomplish other tasks, such as a discussion leader assignment, a final presentation about her host family, journaling, etc. In the end, we allowed Cassidy to continue in the course and she was able to complete the requirements of the course. We also learned that having one of the faculty work daily and individually with Cassidy to go through the details of the schedule improved the situation to a degree.

Yet, overall, the daily issues with Cassidy did not cease and she continued to require an inordinate amount of time from faculty members and staff alike. By the third week in Ecuador, it was also agreed that, in addition to having some form(s) of disability, which we were yet to determine, Cassidy was also a master manipulator. She was successfully able to become the center of attention in all situations, and while some instances were certainly associated with disability, others, we believe, were simply attention seeking and tied to other aspects of her personal trajectory. She would repeatedly seek assistance from students with the most basic tasks, including buttering bread during breakfast, a task she could certainly complete herself. The other students in the class became increasingly tuned in to Cassidy's behavior and would intervene every time they anticipated situations as those described above.

\section{Case Study 2: Working with Claudia}

Claudia registered for the "Summer in the Andes" program after meeting with the program director, also one of the authors of this article. She knew Claudia well from past courses, and had already worked to make various adjustments in the classroom to effectively address her learning experiences as a student with ASD. While there was undoubtedly concern as to whether the study abroad experience would be a good fit for Claudia, there were four reassuring factors: 1) prior rapport with the faculty director; 2) the student's self-awareness and disclosure of being in the autism spectrum, and in turn, her readiness for effective self-advocacy; 3) her cultural navigation skills as a result of her experience as a Mexican young woman (Claudia moved to the United States with her family when she was 11 years old); 4) the support provided by the student's social networks, namely her family in the United States and their direct communication with her host family in Ecuador. In the end, not only did Claudia have a growing and memorable experience but, we argue, 
her presence contributed to theoretical and practical improvements in the study abroad program as a whole.

Muggleton (2012) lists many impairments that manifest in the areas of difficulty for people with Asperger's, many of which were evident in Claudia's behavior throughout the program: pedantic speech and literal understanding, lack of understanding of social rules, frustration at communication problems and at being different, and focused rather than flexible thinking. Clearly aligned with the aforementioned behaviors, Claudia needed to be able to predict what was going to happen, her focus or interest was often narrow, and she felt a strong need to stick to the familiar. She certainly brought up situations previously unknown to the program faculty. Yet, her self-awareness and self-advocacy allowed her to express herself clearly, request assistance, and address each problem with admirable effectiveness. Overall, Claudia often provided explanations for her behavior to facilitate communication. For instance, upon forgetting her stuffed animal on the first night at a hotel in Quito, she reasoned her way through her anxiety while asking for help: "I wonder if it could be mailed to me or if we could get it. I know a stuffed animal is not that important. I apologize, and $I$ understand it is not very important, but it helps me to sleep, and it will be hard for me to sleep without it, but I know that it is not important." This fragment of her speech shows her awareness of her personal experience versus social expectations. In a maturity rarely evident in students abroad, Claudia is drawing a clear line between her personal need and expectations from others. She does not blame or demand, but rather explains and requests.

Claudia often explained her behavior as an expression of Asperger's, and as a result, what could have been conveyed as insistent and inflexible behavior became in fact an illustration of precisely the contrary. Because of Claudia's ability to speak for and about herself, faculty, staff, and students found her behavior not only bearable, but a laudable illustration of how to challenge oneself and work through discomfort. Although admittedly time-consuming on occasion, it was gratifying to work with a student who showed such readiness to overcome difficulties. Her direct communication with her parents, and particularly with her mother, allowed her to find support through various venues simultaneously, and her uneasiness would give way upon confirming that her various support systems (family, host family, faculty, and staff) all assured her she'd be all right at moments that would trigger anxiety (losing things, confronting loud noises or new food textures, and all the challenges of navigating her way in a new city and with a new routine). There is no doubt that Claudia struggled to understand what was going on, but her keen awareness of her need to read people's reactions often countered the very fact that she had difficulty doing so. In other words, she hyper-compensated for what she knew was an expected limitation of ASD, becoming in turn a careful observer of cultural expectations, practices, and behaviors, and thus, an exemplary student abroad.

Despite Claudia's experience being a success story overall, there are many examples that raise flags about the need for all involved in the study abroad experience to be aware of some of the patterns tied to ASD. To give one example, Claudia struggled during every hiking experience, and would refer to her general lack of coordination as "clumsiness" when in fact, as we later learned, ASD sometimes manifests as problems with the proprioceptive and vestibular senses. The former enables the brain to know where the body is in relation to itself (Muggleton, 2012), while the latter regulates balance. Claudia often fell down while hiking, scraped parts of her body against bushes 
and rocks, or at the very least tripped. We worked out various methods to assist her throughout these experiences, but it would have been helpful to know that they were also part of ASD, as well as that people on the autistic spectrum are often subject to hypersensitivity, hyposensitivity, or other sensory problems (Muggleton, 2012). It follows that we should not have simply asked Claudia if she was all right every time she fell. She always answered that she was. But, in fact, we later learned that, as a result of ASD, she could have had an extremely high tolerance for pain. Luckily, none of her repeated falls resulted in anything serious, but the danger that we could have underestimated something more serious is evident.

Muggleton reminds us that, "Just because someone with AS or autism looks fine, it doesn't mean they are" (p. 35). We only became alert to this after the program, when conducting research for this paper. In its aftermath, we realize we did not have the tools, even with Claudia's guidance and self-assertiveness, to read fully into her experiences to ensure the best outcomes. Students in the autism spectrum, we have learned, are more prone to depression and anxiety, and although we celebrate Claudia's case study as a successful one, things could have gone awry due to our general unawareness of the ASD experience.

In a study abroad program, students are faced with a completely new environment, and for students with ASD the stakes of these challenges are especially high. People with ASD have trouble with new environments. It is a Herculean effort for some to confront things as simple as new food, textures, or smells. They need a routine, feel safest with rigid behavior, and obsess about many things that seem inconceivable to those outside of their worldview. We encourage students in study abroad programs to step out of their comfort zones, try new things, and embrace new routines, precisely the areas that are most challenging for students with ASD. Yet, Claudia's case shows that this is possible. Collaboration between the student and faculty, outside program partners, host family, and family at home proved key to Claudia's positive experience while in Cuenca. Her case also allowed us to think about our work as faculty and program directors. For instance, students like Claudia remind us of the need to be more thorough in our messages and the means to convey them. With Claudia, we learned to be careful and, for example, not announce a departure at 8 a.m. if we anticipated some flexibility. Instead, we would explain that we would leave "closely after eight," and that simple gesture, while perhaps harder to understand at first, eased the anxiety of a late departure. As Muggleton (2012) explains, "We like to know what is going to happen, so it's helpful if a brief itinerary is written down somewhere (on the whiteboard or on paper). This is particularly important where a routine has yet to be established" (pp. 150-151). No doubt, this cue from Muggleton is key to the overall success of the study abroad program, and while flexibility is certainly necessary, the ways in which we address such flexibility can be most welcome for students like Claudia. Furthermore, the implementation of relaxation techniques and reflective exercises, which certainly helped Claudia, increased the overall quality of the program as a whole and for all students. The combination of factors, faculty-student rapport, the student's awareness and self-advocacy, cultural navigation skills, and articulation between social networks, although not always easy, allowed us to "meet in the middle," and as such, we all grew in our cultural approximation to each other in our new environment.

\section{Study Abroad and Students on the Spectrum: Challenges and Possibilities}


Working with students with ASD in study abroad initiatives offers an array of challenges and possibilities - legal, pedagogical, and practical. Institutions of higher education must assure access to equal opportunity ${ }^{4}$ and, because study abroad experiences are increasingly part and parcel of the general curriculum, it is clear that institutions of higher education must strive to address these initiatives with attention to the diversity of the student body. For students with ASD, it is important to outline each program as meticulously as possible to assure that communication begins during the very process of choosing a study abroad program. The two case studies above highlight the importance of faculty-led programs in collaboration with a program partner, and contrary to expectations, call for long-term over short-term programs. For students with ASD, it is important to establish a routine, and long-term programs are more conducive to this process than shorter programs that lack consistency in a daily routine. In addition, unless the student with ASD is seeking immersion in a second language, the challenges are best countered in one's own language. Above all, both cases above highlight the need to think about communication between the student's family and the college, across campus entities, and between the student and faculty.

\section{Communications across Institutional Entities}

It is imperative that institutions have protocols in place for proper communication between various offices across campus. In the first case study, if applicants (or names of applicants) would have been shared with disability services, perhaps some advice, or potential concerns, could have been expressed to the faculty. Moreover, consultation with campus health may have brought to light the need for the specific medications Cassidy listed on her health forms. When a student chooses to not disclose, or does not understand the importance of fully completing such forms, advice from trained medical staff would be useful for faculty. On many campuses these lines of communication between offices should be formalized and centralized through mechanisms established by the study abroad office or its equivalent at a given institution.

We also recognize the legal hurdles involved in such recommendations. Often, staff and administrators in disability services, counseling, or student health are bound by confidentiality agreements and legal clauses. While these laws are no doubt a critical protection for students, a way to inform faculty of potential concerns associated with a given student needs to be created. Perhaps a waiver of confidentiality related to disabilities could be encouraged by trained staff in instances involving high risk to the student or other students in the course. In the end, it would still be up to the student to sign or not, but a discussion of the importance of informing the faculty could be had between the student and the appropriate staff. Even if a student decides not to sign a limited confidentiality waiver, at least more open and direct communication between student and faculty would be more likely.

\section{Communication Between Faculty and Student}

\footnotetext{
${ }^{4}$ The ADA laws were created in 1973 to assist disability students in higher education. Under Section 504, Subpart E (Postsecondary Education) of the 1973 Rehabilitation Act and the Americans with Disabilities Act, "institutions of higher education must provide reasonable accommodations to a student's known disability and may not deny equal access to the institution's programs, courses and activities" (U.S. Department of Education, 2011). ADA laws for college students can be accessed at http://www.2.ed.gov/about/offices/list/ocr/transition.html.
} 
This leads directly to the equally important aspect of communication between students and faculty. Establishing a sense of trust early on between faculty and student is important. All students should be encouraged to fully disclose any concerns they have about engaging in such an experience. Faculty should also assume students are often not comfortable doing so. Therefore, it is imperative for faculty to properly orient students for the upcoming study abroad experience. By orienting them to the many challenges they will face in immersive experiences, perhaps the likelihood that students will self-disclose important details of their personal situations will increase.

Faculty should also stress the importance of disclosing information during their orientations with students. The timing of this type of orientation is crucial as well. The earlier this sort of orientation occurs, the sooner disclosure by students may also occur. This therefore provides the faculty with ample time to strategize on and prepare for making appropriate accommodations. For instance, in Cassidy's case, if faculty had known more about her condition and coping mechanisms in advance, adequate consideration and accommodations could have been made. As Cassidy struggled the most with a change in her routine, faculty could have assisted in better preparing Cassidy for the new daily experiences and routine. By giving Cassidy direct information about how her daily routine would differ from normal, perhaps Cassidy could have worked directly, as did Claudia, on developing coping skills needed to overcome these new obstacles. This sort of direct communication between faculty and student is the key difference between the two case studies presented. Cassidy was not willing (or able) to ever discuss why she needed to behave in certain ways, leaving faculty only to guess, which led to an increase in frustration and an imbalance of time spent focusing on Cassidy instead of on other students in the course.

\section{Additional Support Systems}

During the study abroad experience, ASD students need extra support systems in place and, no doubt, the process is not free of challenges. Some barriers to the provision of inclusive postsecondary education, as indicated by Zager et al. (2013), include: a) low expectations and inadequate preparation; b) lack of available supports and services in institutions of higher education; c) negative attitudes in academic cultures; d) lack of faculty knowledge to accommodate diverse learners; and e) lack of access to financial support. Yet, study abroad initiatives attentive to the reality of ASD students work to the benefit of the student body as a whole. Thus, careful attention to scheduling and planning, implementation of self-relaxation techniques and exercises in the schedule, and a whole system of initiatives with attention to Universal Design for Learning (UDL) ${ }^{5}$ should, we believe, be integrated and folded into the totality of the study abroad experience, not specifically under the premise of supporting ASD students, but rather because these steps assure the overall quality of a program for all parties involved. This awareness is contingent upon the move from a medical model of disability to an understanding of disability as a social, cultural, and political phenomenon. Bluntly put, we cannot address the variety of the cultural groups on our campuses without responding to the glaring absence of students with disabilities. For those of us who address

\footnotetext{
${ }^{5}$ Universal Design for Learning (UDL) is a framework for the design of materials and instructional methods useful to a wide range of students. UDL aims to provide full access to students with special needs, while improving the learning experience for all students, through attention to multiple sensory avenues and a variety of conceptual frameworks (see Gronneberg \& Johnston, 2019). For an ample overview of UDL research and reach, please access the CAST website at www.cast.org.
} 
cultural processes in our scholarship and teaching, and who therefore know the value of study abroad experiences, reflecting on the cultural construction of students with disabilities, including ASD students, is a must.

\section{Students with ASD: Cultural Observers Abroad}

While sociocultural challenges are largely the objectives of any study abroad experience, it does not follow that students with ASD are "unfit" for study abroad. While the case studies above illustrate different outcomes for students with ASD, both provide insights into how study abroad practitioners could increase the likelihood of successful experiences. In one case, it was precisely because of the student's challenges that the student had no option but to constantly work on her abilities to observe human behavior, and, as part of that process, was often painfully conscious of the importance of observing cultural codes, as well as of the need for self-awareness in cultural/social encounters. By being what Collins (1999) called the "outsider within," the student was placed in a situation that actually sharpened her skills in cultural observation and furthered her ability to be self-aware in a new cultural context. These are precisely the skills that aid in the development of cultural competency, the desired outcome for any student that studies abroad. In the case of Cassidy, more pre-departure work was needed, across a variety of campus offices, to ensure she was willing and able to work on her reflexive skills. However, a different experience seemed to emerge from Cassidy's case. While Cassidy's coping mechanisms for dealing with all of the changes present in such an experience (daily routines, cultural, etc.) were not ideal, they did have the benefit of making often invisible patterns of social interactions, and thereby social norms, plainly visible to the other students in the course. In essence, Cassidy's case was a great example of a breaching exercise that was being conducted on the other students in the course. Nearly every day, in a variety of contexts and situations, the students were confronted with violations of social customs from their home culture. This made them keenly aware of engrained, but normally invisible, cultural customs and norms. Ultimately, this also had the effect of creating a hypersensitivity to avoiding breaking social customs and norms. They were therefore more self-aware of their own behavior in regards to their place within a culture different from their own. The students were quicker to pick up on the behavior of others that would indicate a violation of a cultural norm and were therefore able to acclimate to specific cultural context with more ease. This is not to say that cultural customs and norms were not broken by the students, as they surely were, but rather that because of Cassidy's presence in the course, the students were afforded the opportunity for self-awareness and reflection that otherwise may not have occurred.

Both cultural observation and self-evaluation are central objectives of a university's drive to provide opportunities for cultural competency. Thus, although the participation of students in the autism spectrum poses plenty of challenges, their increasing access to study abroad opportunities could enhance the study abroad experience. As such, while the challenges are many, we move from a framework that adjusts to the needs of these students to an inquiry into the ways in which they can contribute to enrich the study abroad experience. The case studies presented here certainly show how an inclusive program, through proper orientation mechanisms, could be beneficial for all participants' self-awareness and ability to reflect.

\section{References}


Anzaldua, Gloria. (1987). Borderlands/La Frontera: The new Mestiza. San Francisco, CA: Aunt Lute Books.

Armstrong, F., \& Barton, L. (1999). Disability, human rights, and education: Cross cultural perspectives. Philadelphia, PA: Open University Press.

Autistic Self Advocacy Network (ASAN). (2013). Empowering leadership. A systems change guide for autistic college students and those with other disabilities. Washington, DC: Autistic Self Advocacy Network.

CAST until learning has no limits. (2019). UDL at a glance. Retrieved from http://www.cast.org/ourwork/about- udl.html\#.XdL5AC2ZOqA

Collins, P. H. (1999). Reflections on the outsider within. Journal of Career Development, 26(1), 85-88.

Dwyer, M. M. (2004). Charting the impact of study abroad. International Educator, 13(1), 14-20.

Garfinkel, H. (1967). Studies in ethnomethodology. Malden, MA; Blackwell Publishers.

Goffman, E. (1959). The presentation of self in everyday life. New York, NY: Anchor Books.

Goffman, E. (1963), Stigma: Notes on the management of spoiled identity. Englewood Cliffs, NJ: Prentice-Hall.

Gronneberg, J., \& Johnston, S. (2019). Seven things you should know about Universal Design for Learning. Retrieved from http://library.educause.edu/-/media/files/library/2015/4/eli7119/-pdf

Ingersoll, I. (2016). College success for students with disabilities. A guide to finding and using resources, with real-world stories. Jefferson, NC: McFarland and Company, Inc.

Institute of International Education. (2003). Host regions and destinations of U.S. study abroad students, 2000/01-2001/02. Open Doors report on international educational exchange. Retrieved from http://www.iie.org/opendoors

Institute of International Education. (2017a). Profile of U.S. study abroad students, 2004/05- 2015/2016. Open Doors report on international educational exchange. Retrieved from http://www.iie.org/opendoors

Institute of International Education. (2017b). Detailed durations of U.S. study abroad, 2005/062015/16. Open Doors report on international educational exchange. Retrieved from http://www.iie.org/opendoors

Institute of International Education. (2017c). Top 25 destinations of U.S. study abroad students, 2014/15 2015/16. Open Doors report on international educational exchange. Retrieved from http://www.iie.org/opendoors

Katovitch, D. M. (2009). The power to spring up. Postsecondary education opportunities for students with significant disabilities. Bethesda, MD: Woodbine House, Inc.

Lightner, K. I., Kipps-Vaughan, D., Schulte, T., \& Trice, A. D. (2011). Reasons university students with disabilities wait to seek disability services. Journal of Postsecondary Education and Disability 25(2), 145-159.

Link, T. C. (2016). Strategies and challenges for creating an inclusive study abroad program. Journal of Postsecondary Education \& Disability, 29(3), 293-298.

Metzger, C. A. (2006). Study abroad programming: A 21st century retention strategy? College Student Affairs Journal 25(2), 164-175.

Muggleton, J. (2012). Raising Martians. From crash-landing to leaving home. How to help a child with Asperger syndrome or high-functioning autism. Philadelphia, PA: Jessica Kingsley Publishers.

National Center for Education Statistics. (2011). Students with disabilities at degree-granting postsecondary institutions. Washington, DC: Institution of Educational Sciences, U.S. Department of Education.

Prohn, S. M., Kelly R., \& Westling, D. (2018). Students with intellectual disability going to college: What are the outcomes? A pilot study. Journal of Vocational Rehabilitation, 48(1), 127-132.

Sandoval, C. (2000). Methodology of the oppressed. Minneapolis, MN: University of Minnesota Press.

Simmel, G. (1921). "The stranger": On individuality and social forms. Chicago, IL: University of Chicago Press. 
Tinto, V. (1993). Leaving college: Rethinking the causes and cures of student attrition. Chicago, IL: University of Chicago Press.

Twill, S. E., \& Guzzo, G. R. (2012). Lessons learned from a disabilities accessible study abroad trip. Journal of Postsecondary Education \& Disability, 25(1), 81-86.

U.S. Department of Education. (2011). Students with disabilities preparing for postsecondary education: Know your rights and responsibilities. Washington, DC: Office for Civil Rights, U.S. Department of Education.

Wolf, L. E., Brown, J. T., \& Bork, G. R. K. (2009). Students with Asperger syndrome: A guide for college personnel. Shawnee Mission, KS: Autism Asperger Publishing Company.

Zager, D., Alpern, C., McKeon, B., Maxam, S., \& Mulvey, J. (2013). Educating college students with autism spectrum disorders. New York, NY: Routledge. 